\title{
ILCEA
}

Revue de l'Institut des langues et cultures

d'Europe, Amérique, Afrique, Asie et Australie

35 | 2019

Intermédialités dans les arts et la littérature de

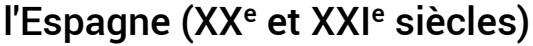

\section{La emisora primordial: Entrevista a Agustín Fernández Mallo y Eloy Fernández Porta}

La emisora primordial : entretien avec Agustín Fernández Mallo et Eloy

Fernández Porta

La Emisora Primordial: Interview with Agustín Fernández Mallo and Eloy

Fernández Porta

\section{Alice Pantel}

\section{OpenEdition}

\section{Journals}

Edición electrónica

URL: http://journals.openedition.org/ilcea/6363

DOI: 10.4000/ilcea.6363

ISSN: 2101-0609

Editor

UGA Éditions/Université Grenoble Alpes

Edición impresa

ISBN: 978-2-37747-083-9

ISSN: 1639-6073

\section{Referencia electrónica}

Alice Pantel, «La emisora primordial: Entrevista a Agustín Fernández Mallo y Eloy Fernández Porta », ILCEA [En línea], 35 | 2019, Publicado el 27 marzo 2019, consultado el 19 mayo 2020. URL : http:// journals.openedition.org/ilcea/6363 ; DOI : https://doi.org/10.4000/ilcea.6363

Este documento fue generado automáticamente el 19 mayo 2020.

(c) ILCEA 


\section{La emisora primordial: Entrevista a Agustín Fernández Mallo y Eloy Fernández Porta}

La emisora primordial : entretien avec Agustín Fernández Mallo et Eloy Fernández Porta

La Emisora Primordial: Interview with Agustín Fernández Mallo and Eloy Fernández Porta

\section{Alice Pantel}

\section{A F TERPQP \\ FERNÁNDEZ Y FERNÁNDEZZ}

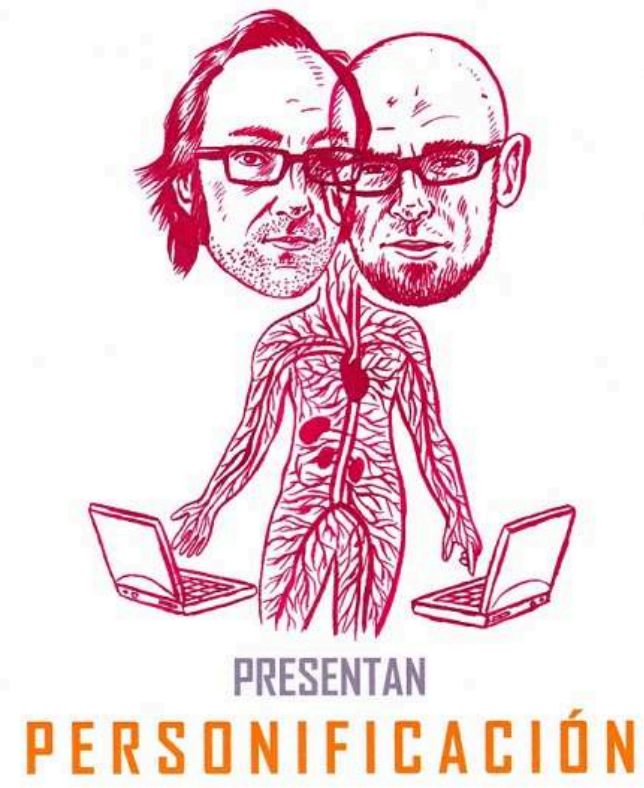


1 Agustín Fernández Mallo es el autor del proyecto Nocilla (Alfaguara, 2008-2009), cuya primera parte, Nocilla Dream (Candaya, 2006), inició el movimiento literario «mutante» que reúne a una decena de escritores deseosos de experimentar las vías creativas abiertas por las nuevas tecnologías. Ya se han dedicado muchas páginas al análisis de las novelas escritas en el marco de este movimiento y en particular a la influencia de las TICs en la propia escritura. Hemos considerado «intermediales» las novelas aumentadas que se prolongan más allá del objeto libro mediante enlaces a textos ajenos, videos, sonidos o capítulos extras en línea. Agustín Fernández Mallo, un escritor músico, videasta y bloguero, se aprovecha de todas estas posibilidades de creación en su trabajo de escritura, lo que tiene como consecuencia la expansión de sus novelas más allá de su formato tradicional, permitiéndole elegir el modo de expresión más adecuado según la idea que quiere transmitir ${ }^{1}$.

2 En el 2008, Fernández Mallo dio un paso más en el proceso de intermedialidad literaria, experimentando un nuevo tipo de propuesta híbrida en colaboración con el ensayista Eloy Fernández Porta, autor, entre otros, de Afterpop. La literatura de la implosión mediática (Berenice, 2007) y representante del marco teórico del movimiento mutante.

«Afterpop: Fernández y Fernández» es el nombre que Fernández Mallo y Fernández Porta dieron a estas sesiones de literatura en vivo. Desde 2008, fecha en la que estrenaron las sesiones en el congreso malagueño «Mutaciones», el evento fue acogido en centros culturales, universidades, librerías y bares en España, Francia, Estados Unidos, Argentina y México. Según los autores, la idea surgió después de una presentación de un ensayo de Eloy Fernández Porta en Palma de Mallorca para escapar del formato tradicional de promoción de un libro. Rápidamente, los dos escritores decidieron colaborar y crear «Afterpop: Fernández y Fernández» sin que estas sesiones estuvieran ligadas al proceso de comercialización de un libro a fin de llegar a ser un evento per se.

Generalmente, dichas sesiones se desarrollan en un escenario: los dos escritores, de pie delante de una pantalla gigante en la que proyectan extractos de películas, imágenes, publicidades, fotos propios o bajados de YouTube, declaman sus textos. El fondo musical suele ser música pop, rock o electrónica.

5 Hasta ahora, los trabajos de investigación principales se han centrado en lo que en otras páginas hemos llamado «intermedialidad interna», o sea la influencia de las Nuevas Tecnologías en la producción narrativa clásica. En el caso de «Afterpop: Fernández y Fernández», se trata más bien de «intermedialidad externa», o, en otros términos, del movimiento de escape de la literatura fuera de su ámbito natural, que es el libro. Este proceso de «espectacularización» de la narrativa nos resultó interesante en la medida en que varios factores como el cuerpo y la voz del escritor, la música y el sonido, la confrontación directa con el público entran en juego en estas sesiones y vienen a modificar profundamente la relación tradicional del trinomio lector-novelaautor.

6 ¿Cómo se denomina este tipo de evento y en qué sector semiótico se inscribe? ¿Tenemos que considerarlo como parte íntegra de la obra de un autor? ¿Cuáles son las consecuencias de la transición entre la palabra muda y la palabra viva en el proceso de creación y de recepción? ¿Puede considerarse este tipo de evento como el signo de una tridimensionalidad de la narrativa, fuera de las normas propias de las artes escénicas? 
7 A modo de trabajo preparatorio a un estudio sobre la espectacularización de la novela, hemos querido recoger el testimonio de los creadores y dirigir estas preguntas directamente a los autores.

8 La entrevista que publicamos a continuación tuvo lugar después de una de estas sesiones, el 21 de marzo de 2015, en el Centro Dramático Nacional hTh de Montpellier (Francia) en el marco del festival de Spoken Word organizado por el escritor, periodista y músico español Bruno Galindo.

¿Slam, spoken words, espectáculo, show, performance, happening, concierto, cómo tenemos que llamar lo que acabamos de ver?

\section{Eloy Fernández Porta (EFP):}

La palabra espectáculo está bien. Cuando empezamos a trabajar, en el año 2008, los espectáculos no tenían nombres específicos, se llamaban «Fernández y Fernández». El nombre se le ocurrió al escritor Germán Sierra. Cuanto más trabajábamos, más actuaciones hacíamos. Se nos ocurrió entonces generar un espectáculo con un concepto. Siempre manejamos diez temas (cinco de Agustín y cinco míos). De hecho, es la primera vez desde el 2008 que hacemos 12 temas. Es una cosa que ha ido evolucionando cada vez más, de modo que el show anterior se llamaba «Personificación» y este «La emisora primordial». Ya hemos hecho varias sesiones en varios sitios con la idea de lo primordial, de lo primitivo, de las primeras voces. Ha sido muy interesante que antes de nosotros actuara Blixa $^{2}$ porque aquella canción que ha hecho sobre la formación del sistema solar creado con ecos y luego con la selva es una canción que podría entrar perfectamente en nuestro show.

¿Los textos declamados en estas sesiones son textos ya publicados o inéditos?

Agustín Fernández Mallo (AFM):

Hay de los dos. Cada uno hemos cogido de lo que hemos publicado y los hemos «customizado». Y hay otros que son totalmente nuevos, escritos para esto. Son textos de poesía en su mayoría. El 70\% de lo que leo es poesía de poemarios publicados o del nuevo poemario que saldrá a finales de este año.

\section{EFP:}

De los 6 textos que he leído hay uno que sale de mi último ensayo que he publicado Emociónese así y varios más que forman parte de los dos libros que estoy escribiendo ahora. Son ensayos, pero los concibo como un texto total. En mis ensayos, sin embargo, hay dos poemas narrativos que siempre traslado a las sesiones de Spoken Word. La parte que funciona más como poesía oral, es lo que uso.

¿El último texto de la función, sobre Nietzsche, se parece mucho a los textos «Mutaciones» que aparecen en El Hacedor de Borges Remake? De hecho, en estas sesiones existen muchos ecos entre la narrativa de Agustín Fernández Mallo (profusión de citas, teorías científicas).

En el momento de la creación, ¿existe una diferencia entre escribir un texto para publicar y escribir un texto para declamar?

\section{EFP:}

Para mí, hay textos que funcionan escritos pero que no funcionan en voz alta y viceversa, con lo cual lo que hacemos es ensayar juntos en su casa y recitar aquellas partes que son literatura expandida, las partes que funcionan como canción. Y como utilizamos teorías de crítica cultural de dos maneras diferentes, en su caso integradas 
a la literatura y en el mío a textos ensayísticos, hay algunas partes que funcionan particularmente bien.

«Un fantasma recorre Europa», «La mujer no existe», «bienvenidos al desierto de Loreal» son ideas. Pero si esas ideas han tenido extensión y éxito es porque funcionan como silogismos, porque son impactantes literariamente, porque son emocionantes.

AFM:

De hecho, este texto sobre Nietzsche forma parte de una novela que aún no ha salido. Aunque haya sido originalmente escrito como un texto, tiene un componente oral, tienen una cadencia, son como eslóganes. Sin embargo, creo que hay algo que los diferencia: es que en todo este paquete de textos que extraemos de la propia textualidad para hacerlos orales, hay una parte intuitivamente controlada de sobreinformación. Hay cosas que no terminan de encajar del todo con la oralidad, entonces creo que es un transgresor que usamos. Introducir en la oralidad este concepto que es más textual que oral y que queda a veces una sobreinformación. Es video, música, texto. Jugamos con esta sobreinformación como metáfora o símbolo material de la contemporaneidad. Evidentemente hay una gran diferencia entre lo que hacemos nosotros y el típico poema recitado con música. La diferencia con el slam es que rompemos las cadencias. Creo que es la cosa que más nos caracteriza, llegar al punto de sutileza en que hacer eso sin que sea insoportable para el espectador.

Yo lo imagino principalmente como una cosa textual. El término performance se ha aplicado a veces para calificar lo que hacemos, pero literatura live, Spoken Word o literatura oral es mucho más apropiado porque, para nosotros, la música y la imagen tienen una importancia secundaria y los elementos escénicos son bastante mínimos. Una performance pertenece al ámbito de las artes escénicas y tiene un trabajo sobre el cuerpo o sobre el espacio teatral que no hacemos nosotros.

Es una literatura que se escapa pero que no deja de ser literatura. La cuadratura del círculo: lo interesante es llevar la literatura a un escenario sin que deje de ser literatura, sin que seamos performers, cantantes por supuesto, actores de teatro. La idea es desplazar un texto de su ámbito natural para ver cómo deriva y qué pasa con todos esos elementos.

\section{EFP:}

Luego la respuesta del público cambia en función de los espacios. En México, quizás porque están acostumbrados a un tipo de puesta en escena muy aparatosa, la reacción fue como si vieran una obra de teatro. También cuando estás trabajando en el escenario lo percibes de manera diferente que cuando trabajas el texto en casa. En casa, lo primero que haces son notas, cuando te pones a escribir, primero trabajas con una idea narrativa o un concepto. Trabajas con páginas y capítulos. Cuando coges este texto y lo empiezas a trabajar para recitarlo, trabajas con frases. Y cuantas más veces lo has repetido, cuando ya estás en el escenario, trabajas con sílabas, fonemas. Eres mucho más consciente de la sonoridad, de la ecualización, de la voz, de los valores 
fónicos. Te has olvidado de la parte conceptual del texto. El traslado de las cualidades de la escritura al ámbito vocal es el gran cambio que se da.

¿La presencia física frente a un público no perturba la tradicional soledad del escritor?

Es importante, pero a mí no me interesa nada este aspecto. Lo hago porque Eloy es mi amigo, pero no lo haría solo ni con otro. No estoy dotado para eso, no me gusta. Estoy mucho más cómodo sentado detrás de una mesa, como un profesor dando una clase. Con esto quiero decir que, a mí, el asunto de la presencia física en un escenario me incomoda, pero bueno, es un precio que hay que pagar para hacer algo. Como a veces me incomoda quedarme en casa para escribir, pero es el precio que hay que pagar para hacer algo que te interesa. $\mathrm{Y}$ admito que no tengo mucha conciencia de lo performativo, ni de la actuación. Recito como un robot. Y me gusta mucho investigar todas esas técnicas de lo inhumano que recita como un robot. Lo combinamos también porque Eloy se mueve mucho más, tiene muchas más facilidades en el escenario, sale, entra. $Y$ creamos un contraste que funciona.

\section{EFP:}

Son contrastes que se han ido desarrollando de muy distintas maneras. Cuando empezamos a hacerlo, el contraste básico era que Agustín tenía una presencia escénica más fría, más estática, mientras que mi presencia escénica era un poco más payaso. Y luego los contrastes son ensayísticos porque Agustín tiene cosas de física, de arte conceptual de Robert Smithson y hay textos míos, aunque nunca haya escrito poemarios, que son poemas narrativos.

¿Cómo se construye la relación entre los textos, las imágenes y la música?

\section{EFP:}

Cada uno trabaja en su casa, escribimos, buscamos, montamos la música y los videos y luego nos lo pasamos por email y lo comentamos. Pero no solemos intervenir mucho en el trabajo del otro. Lo más habitual es que lo que le envié le gusta y viceversa. Siempre es muy fluido. Y luego repetimos. La actuación, la solemos utilizar como un ensayo para ver cómo reacciona el público y así podemos testar qué respuesta se obtiene del público, sobre todo el ritmo de la actuación. Hasta que no hayas hecho una actuación no te puedes imaginar cuál es el estado del público cuando lleva 20 minutos o 40 minutos. Hay una canción que funciona como segunda canción, pero no como séptima canción. Y eso por mucho que lo ensayes no lo puedes ver en una sala de ensayo, solo lo puedes ver escuchando y captando la respuesta de los demás. Son doce textos. Esto si lo publicáramos, sería una «plaquette» hecha a mano, titulada La emisora primordial, un libro de miscelánea con géneros bastante distintos pero unificados en el tema o al menos con unas líneas de trabajo común: la primera imagen, el primer neandertal, el origen y el apocalipsis. En el origen está la ruina y entonces existe la simultaneidad del principio y del final. Entonces esta «plaquette» la podríamos adaptar y publicar, podría ser en una editorial de poesía que publican estos libros fuera de género, pero nos parece que ese texto funciona mejor recitado que redactado.

El ensayo son las propias actuaciones. Crea unas dinámicas muy simpáticas. Es un descubrimiento. Todo error lo puedes redefinir en tu beneficio. No somos ni teatro, ni 
performance ni una declamación de poesía, es otra cosa. No voy a dar un nombre, para eso estáis los teóricos.

El término literatura expandida puede incluir esto.

Empezamos en congresos de literatura donde la mayor parte de los actos eran coloquios, mesas redondas, conferencias, y nosotros empezamos a aportar una parte de literatura oral. Luego, en encuentros de poesía en los que hay recitales de forma tradicional o actualizado y también hemos hecho muchas actuaciones en centros de arte y museos de arte contemporáneo.

En esos espacios, el público está más acostumbrado a ver actos públicos que no son espectáculos o que, en momentos determinados, usan elementos espectaculares.

\section{AFM:}

Y que no encajan en una tipología determinada de un género. En los centros de arte, creo que es donde mejor ha funcionado lo que hemos hecho. En una universidad, si es un público de filología española tradicional, a veces les puede coger descolocados.

EFP:

Somos escritores muy interesados en el arte, colaboramos con artistas y es un elemento fundamental para nosotros. Lo es por el espacio que representa el centro de arte. El mundo del arte ya no se puede definir por los formatos, sino que es un espacio de importación, que atrae gente que hace cosas muy distintas. Y este espacio crea un tipo de espectador, que puede ver pinturas y leer novelas tradicionales pero que va adquiriendo el hábito de contemplar actos transmedia que no son ni literatura ni teatro.

24 AFM:

No nos sentimos más cómodos en un lugar u otro, pero el público tiene una sensibilidad diferente.

¿De dónde vienen las imágenes?

\section{AFM:}

Muchas partes tomadas de YouTube, o sea hechas por otras personas y otras que son específicamente montadas. La de Nietzsche es una que monté. Con la música igual. Hay músicas hechas específicamente para el tema y otras bajadas de YouTube. Y todo bastante ecléctico. La idea es importar materiales, irlos combinando sin que importe demasiado el origen.

Además, Agustín filma muchos videos y luego hay material apropiado de YouTube y luego hay un trabajo conceptual con el material con fragmentos de películas, por ejemplo. Lo adaptamos al espacio, por ejemplo, aquí he introducido un extracto de Ballet Mécanique ${ }^{3}$, una película francesa que me gusta mucho porque inventa el erotismo en el siglo xx y en la que el montaje es lo que realmente crea el sentido.

¿Se pierde algo si se lee el texto sin ver el video?

AFM:

Yo diría que se añade un nivel de lectura si se añade el video. 
¿Agustín, puedes explicar tu intervención en el museo de Palma de Mallorca?

AFM:

El museo tenía un fondo y me dieron carta blanca para reordenar la colección y darle otra lectura. Y con esto creé un relato diferente a partir del clone, de la repetición, de la copia con obras a partir del siglo XIX hasta el siglo XXI para ver cómo se copia de una época a otra y siempre con la idea de la copia celular. Una célula se duplica exactamente igual pero precisamente por eso se produce una evolución. Copia+error produce evolución o mutación en la biología como en la cultura.

¿Consideráis que Personificación y La emisora primordial forman parte de vuestra obra narrativa?

AFM:

Para mí, no.

\section{EFP:}

Para mí, sí. Está entramada por varias razones en mi trabajo. Todos los textos que escribo pues los tengo que reescribir muchas veces. Para mí, el proceso de reescritura tiene que ver con la creación de un ritmo y con cierto sentido de la métrica. Después de haberlo trabajado a lo largo de quince redacciones, un paso siguiente lógico es recitarlo. Y también incluyo textos en estas sesiones que escribo cuando ya he terminado un libro y ya estoy con otro, entonces me sirve de puente entre dos textos. Entonces para mí, va muy integrado.

\section{NOTAS}

1. En una entrevista inédita de octubre de 2014, Agustín Fernández Mallo afirmaba que: «el escritor hoy tiene a su disposición muchas herramientas y si lo cree necesario puede y debe usarlas. Se trata de usar herramientas complejas en un mundo complejo al que le corresponde una literatura compleja (¡que no complicada!)».

2. Blixa Bargeld es un músico, compositor y performer alemán que actuó en el mismo festival.

3. Ballet Mécanique es una película experimental de Dudley Murphy y Fernand Léger estrenada en 1924, considerada como la primera película sin guión.

\section{RESÚMENES}

Esta entrevista al autor Agustín Fernández Mallo y al crítico Eloy Fernández Porta propone une reflexión colectiva, a partir del proyecto «Afterpop: Fernández y Fernández», sobre una 
intermedialidad externa que proyecta la literatura fuera del libro con el fin de desarrollar una « espectacularización» del relato en la que intervienen diferentes formas artísticas.

Cet entretien avec l'auteur Agustín Fernández Mallo et le critique Eloy Fernández Porta propose une réflexion commune, à partir du projet «Afterpop: fernández y fernández ", sur une intermédialité externe projetant la littérature hors du livre pour permettre ainsi une « spectacularisation » du récit qui met en jeu différentes formes artistiques.

This interview with the autor Agustín Fernández Mallo and the critic Eloy Fernández Porta proposes a collective reflexion, starting from the project "Afterpop: Fernández y Fernández", on an external intermediality that projects the literature out of the book to allow a "spectacularization" of the novel that involves different artistical forms.

ÍNDICE

Mots-clés: intermédialité externe, littérature et spectacle, performance

Keywords: external intermediality, literature and show, performance

Palabras claves: intermedialidad externa, literatura y espectáculo, performance

\section{AUTOR}

ALICE PANTEL

MARGE, Université Lyon 3 